\title{
Source Parameters of the 2003-2004 Bange Earthquake Sequence, Central Tibet, China, Estimated from InSAR Data
}

\author{
Lingyun $\mathrm{Ji}^{1}{ }^{1, *}$, Jing $\mathrm{Xu}^{1}$, Qiang Zhao ${ }^{1}$ and Chengsheng Yang ${ }^{2}$ \\ 1 Second Monitoring and Application Center, China Earthquake Administration, 316 Xiying Rd., Xi'an 710054, \\ China; xjinggis@163.com (J.X.); zq_gke1990@163.com (Q.Z.) \\ 2 College of Geology Engineering and Geomatics, Chang'an University, 126 Yanta Rd., Xi'an 710054, China; \\ yangchengsheng@chd.edu.cn \\ * Correspondence: dinsar010@hotmail.com; Tel.: +86-29-8550-6645
}

Academic Editors: Zhenhong Li, Roberto Tomas, Zhong Lu and Prasad S. Thenkabail Received: 23 March 2016; Accepted: 14 June 2016; Published: 18 June 2016

\begin{abstract}
A sequence of Ms $\geqslant 5.0$ earthquakes occurred in 2003 and 2004 in Bange County, Tibet, China, all with similar depths and focal mechanisms. However, the source parameters, kinematics and relationships between these earthquakes are poorly known because of their moderately-sized magnitude and the sparse distribution of seismic stations in the region. We utilize interferometric synthetic aperture radar (InSAR) data from the European Space Agency's Envisat satellite to determine the location, fault geometry and slip distribution of three large events of the sequence that occurred on 7 July 2003 (Ms 6.0), 27 March 2004 (Ms 6.2), and 3 July 2004 (Ms 5.1). The modeling results indicate that the 7 July 2003 event was a normal-faulting event with a right-lateral slip component, the 27 March 2004 earthquake was associated with a normal fault striking northeast-southwest and dipping northwest with a moderately oblique right-lateral slip, and the 3 July 2004 event was caused by a normal fault. A calculation of the static stress changes on the fault planes demonstrates that the third earthquake may have been triggered by the previous ones.
\end{abstract}

Keywords: radar interferometry; satellite geodesy; earthquake source observations; deformation; earthquake sequence; Bange earthquakes

\section{Introduction}

From July 2003 through July 2004, a complex earthquake sequence occurred in Bange County on the border between Qinghai province and Tibet, China (Figure 1). According to the China Earthquake Networks Center's (CENC) catalogue [1], the sequence started with an Ms $=6.0$ earthquake on 7 July 2003 (Table 1). The National Earthquake Information Center's (NEIC, United States Geological Survey) catalogue indicated a normal faulting mechanism, whereas the Global Centroid Moment Tensor's (GCMT) database showed a strike-slip mechanism (Figure 1). On 27 March 2004, approximately eight months later, three earthquakes occurred approximately $70 \mathrm{~km}$ south of the 2003 event: a large shock (Ms 6.2, 18:47 GMT) was preceded by two Ms $\geqslant 5.0$ shocks (Figure 1; Table 1). Five events with $M s \geqslant 5.0$ were reported through July (Table 1 ). We list all of the earthquakes with Ms $\geqslant 5.0$, and whether the focal mechanism solutions are subject to normal-faulting or strike-slip mechanisms, in Table 1.

On a regional scale, the epicentral area of the 2003-2004 Bange earthquake sequence is situated in the central Tibetan Plateau. Tectonically, the earthquake sequence occurred in the northern Qiangtang block, approximately $100 \mathrm{~km}$ south of the boundary between the Bayan Har block and Qiangtang block. Generally, active north-south shortening and an east-west extension in central Tibet are accommodated by north-south trending normal faults and conjugate strike-slip faults (e.g., [2]). Previous studies 
indicate that recently active faults within the Qiangtang block range from strike-slip to normal faulting kinematics [2].

Table 1. Catalogue of the 2003-2004 Bange earthquake sequence from CENC (shown as stars in Figure 1).

\begin{tabular}{|c|c|c|c|c|c|c|c|}
\hline \multirow{2}{*}{$\begin{array}{c}\text { Date } \\
\text { (yyyymmdd) }\end{array}$} & \multirow{2}{*}{$\begin{array}{c}\text { Time } \\
\text { (hh:mm) }\end{array}$} & \multirow{2}{*}{$\begin{array}{c}\text { Latitude } \\
\left({ }^{\circ}\right)\end{array}$} & \multirow{2}{*}{$\begin{array}{c}\text { Longitude } \\
\left(^{\circ}\right)\end{array}$} & \multirow{2}{*}{$\begin{array}{l}\text { Magnitude } \\
\text { (Ms) }\end{array}$} & \multirow{2}{*}{$\begin{array}{c}\text { Depth } \\
(\mathbf{k m})\end{array}$} & \multicolumn{2}{|c|}{ Focal Mechanism } \\
\hline & & & & & & GCMT & NEIC \\
\hline 20030707 & $06: 55$ & 34.51 & 89.37 & 6.0 & 13 & $\theta$ & 0 \\
\hline 20040327 & $18: 45$ & 33.92 & 89.20 & 5.8 & 13 & - & - \\
\hline 20040327 & $18: 47$ & 34.01 & 89.22 & 5.5 & 10 & - & - \\
\hline 20040327 & $18: 47$ & 33.95 & 89.37 & 6.2 & 9 & 0 & 0 \\
\hline 20040406 & $10: 30$ & 33.93 & 89.13 & 5.0 & 14 & $\boldsymbol{O}$ & - \\
\hline 20040422 & $10: 02$ & 33.87 & 89.12 & 5.1 & 8 & D & - \\
\hline 20040523 & $02: 22$ & 34.00 & 89.30 & 5.1 & 10 & 0 & - \\
\hline 20040523 & $07: 38$ & 34.08 & 89.28 & 5.3 & 9 & 8 & - \\
\hline 20040703 & $14: 10$ & 34.00 & 89.20 & 5.1 & 6 & 8 & - \\
\hline
\end{tabular}

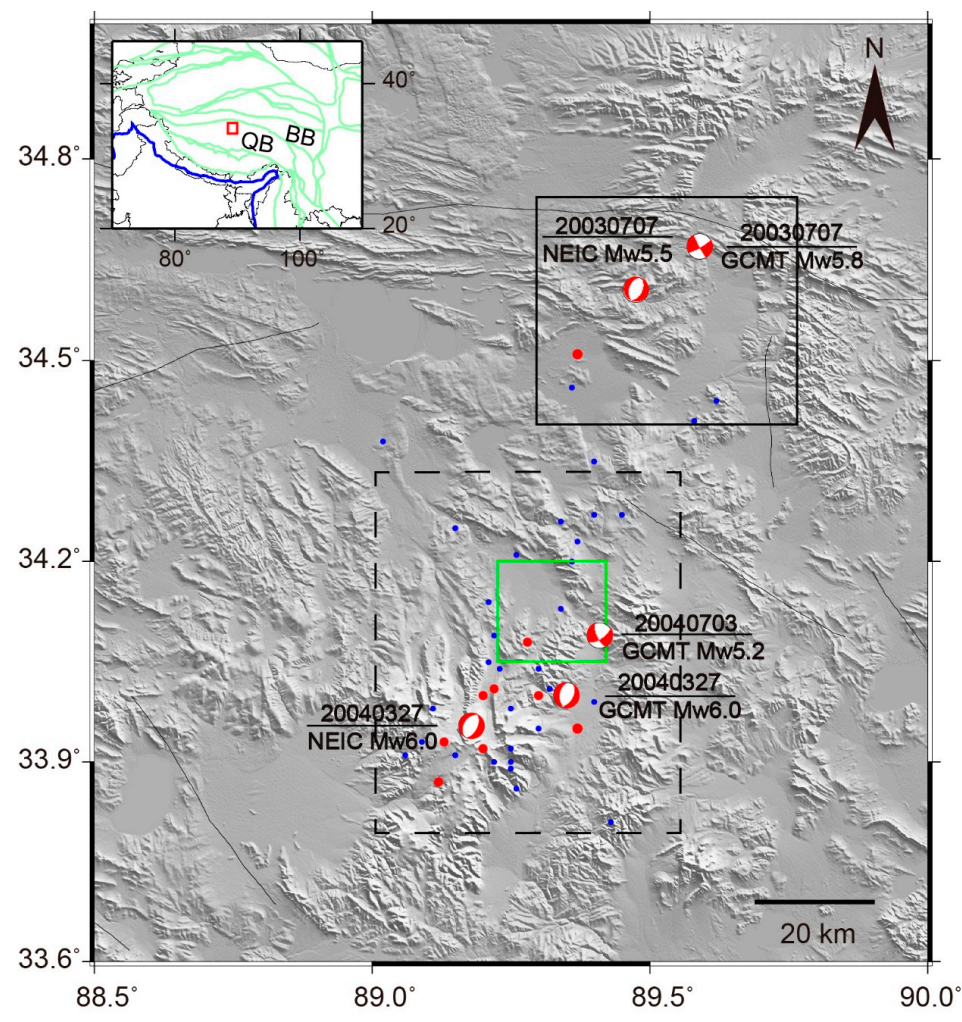

Figure 1. Topographic map of Bange County in central Tibet, China, with the location shown in the inset. Green lines in inset represent block boundaries [3]: BB, Bayan Har Block; QB, Qiangtang Block. Shaded relief topography is SRTM DEM at $90 \mathrm{~m}$ resolution. Black thin lines are fault traces [4]. Earthquakes listed in Table 1 are shown as red circles. Blue circles are aftershocks with Ms $\geqslant 3.0$ through 2015. Earthquake catalogue is from China Earthquake Networks Center (CENC) [1]. Black box with solid line marks areas covered by interferograms of the 7 July 2003 event. Dashed box marks areas covered by interferograms of the 27 March 2004 event. Green box marks areas covered by interferograms of the 3 July 2004 event. Focal mechanisms from NEIC and GCMT for 7 July 2003 Ms 6.0, 27 March 2004 Ms 6.2, and 3 July 2004 Ms 5.1 events are shown. 
According to the China Earthquake Networks Center's (CENC) catalogue (2000 to 2015), earthquakes larger than magnitude 5 were common around the 2003-2004 Bange sequence area; and all of these events were smaller than magnitude 6, except for the two aforementioned events, that is, the 7 July 2003 Ms 6.0 and 27 March 2004 Ms 6.2 events. Thus, identification and characterization of the seismic sources of the 2003-2004 sequence can provide an important contribution to the understanding of the deformation style of this seismically active area. Additionally, the modeling of the displacement fields provides new insights into the seismotectonic setting and the seismic hazard for the central Tibetan Plateau.

Coseismic deformation fields caused by the 2003-2004 Bange earthquake sequence are unknown because of difficult logistics and persistently inclement weather in this remote area. Because of the sparseness of the geodetic arrays, the earthquakes responsible for the sequence were not identified previously. Moreover, the absence of any seismic rupture at the surface after the earthquake does not allow for direct field identification of the seismogenic fault. This makes the application of satellite-based monitoring techniques, such as interferometric synthetic aperture radar (InSAR), highly desirable. InSAR combines two or more SAR images of the same area acquired at different times from nearly the same position in space to map any surface deformation that might occur during the time interval spanned by the images (e.g., [5,6]). InSAR has been well known for imaging coseismic displacements and estimating source parameters since the June $1992 \mathrm{Mw}=7.3$ Landers earthquake (e.g., [7-12]). In this study, we measure the ground deformation due to the 2003-2004 Bange earthquake sequence using InSAR. We invert the source geometries based on the observed surface deformation patterns and subsequently perform linear inversions to retrieve the slip distributions. Then, we evaluate the static stress drop of the 2003-2004 Bange earthquake sequence. Finally, Coulomb failure function (CFF) analysis is used to study the interactions among the earthquakes.

\section{InSAR Data and Analysis}

We collect SAR images covering the 2003-2004 Bange earthquake sequence from the Envisat satellite, operating on the $C$ band. The data are processed using the GAMMA InSAR processing software [13]. We use the two-pass InSAR approach (e.g., [5,6]) to form deformation interferograms. The effects of topography are removed from the interferograms using a filled $3 \mathrm{arc} \cdot \mathrm{s}(\sim 90 \mathrm{~m})$ resolution Shuttle Radar Topography Mission (SRTM) digital elevation model (DEM) [14] obtained from the Consultative Group on International Agricultural Research's Consortium for Spatial Information (CGIAR-CSI) [15]. To improve the signal-to-noise ratio, interferograms are downsampled to 4 looks in range and 20 looks in azimuth $(80 \mathrm{~m} \times 80 \mathrm{~m})$ and are filtered twice using an adaptive filter function based on the local fringe spectrum [16], with the dimensions of the windows being $128 \times 128$ and $32 \times 32$ pixels. This filtering strategy efficiently removes the high frequency noise [17] and makes the phase unwrapping much easier. To remove residual orbit errors, a fine estimation of the interferogram baseline is obtained by a nonlinear least-square adjustment of the observed phase over presumably stable areas $[18,19]$. The time chart in Figure 2 shows the temporal coverage of the coseismic differential interferograms, along with their perpendicular baselines. In addition, marked are the times of seismic events, for reference.

\subsection{The 7 July 2003 Event}

Figure 3 shows two interferograms that span the 7 July 2003 event, mapping the coseismic deformation pattern. The reasonably good coherence permits a clear view of the surface deformation field associated with the earthquake. As the bull's-eye pattern signal is consistent between the two interferograms, which are calculated using two independent pairs of images, we rule out the possibility that the observed signals are strongly affected by atmospheric artifacts. Additionally, the bull's-eye pattern signal cannot be attributed to DEM error because the baselines of these interferograms are short, making them insensitive to any plausible errors in the DEM (Figure 2). 


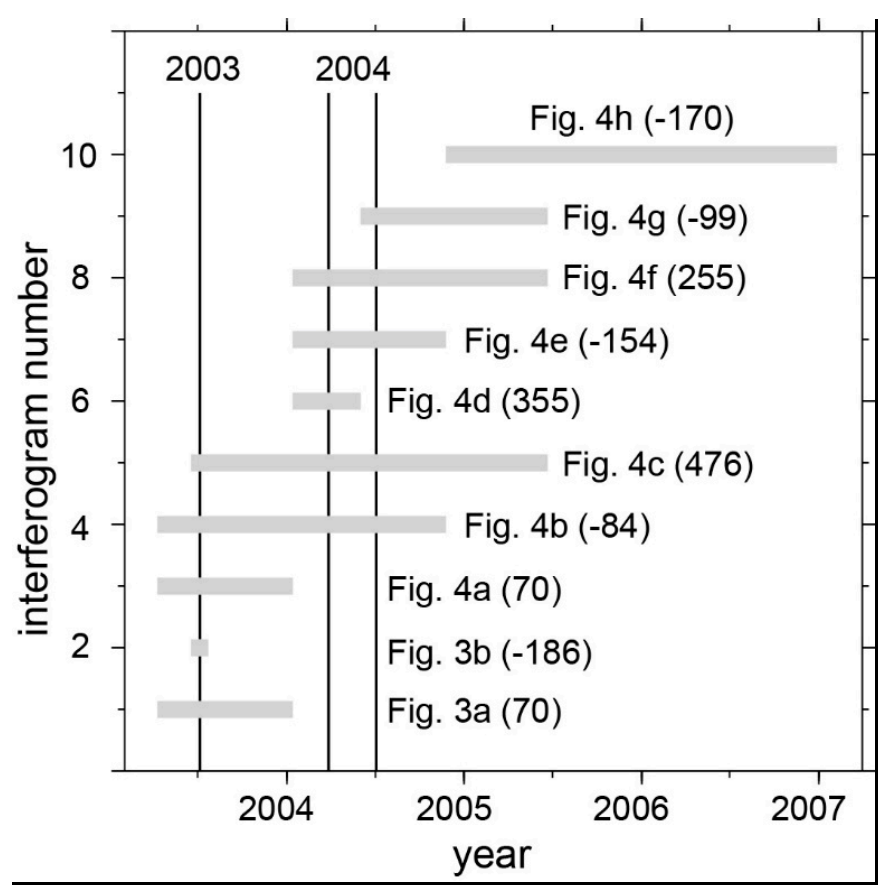

Figure 2. Time intervals covered by each of the interferograms shown in Figures 3 and 4 . Values in parentheses are the perpendicular baseline of each interferogram. Grey bars show time intervals. Black solid vertical lines mark the times of the 7 July 2003 Ms 6.0, 27 March 2004 Ms 6.2, and 3 July 2004 earthquakes (see Table 1 for details).

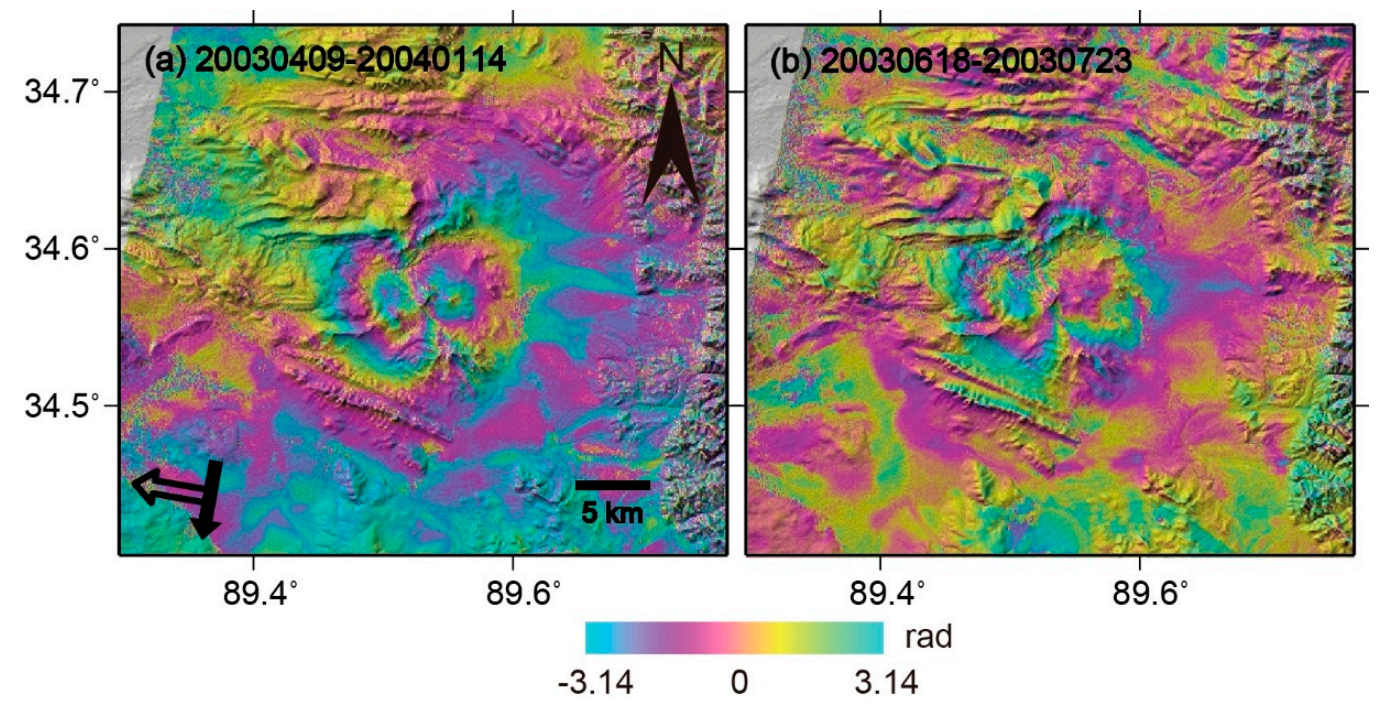

Figure 3. Coseismic interferograms of the 7 July 2003 earthquake. Location of the interferograms is shown in Figure 1 as a box with solid line. Start and end dates are provided above each image using the format yyyymmdd. (a) 20030409-20040114. Satellite flight direction and radar look direction are labeled as a solid arrow and open arrow, respectively; (b) 20030618-20030723. Each fringe, i.e., full color cycle from red through yellow to blue, represents $28 \mathrm{~mm}$ of range increase between the ground and the satellite.

The deformation fields show two approximately symmetric lobes with two color cycles, indicating an approximately $5-\mathrm{cm}$ range change in the radar's LOS (Line Of Sight) direction. The left lobe moved away from the satellite, whereas the right lobe moved towards the satellite. 

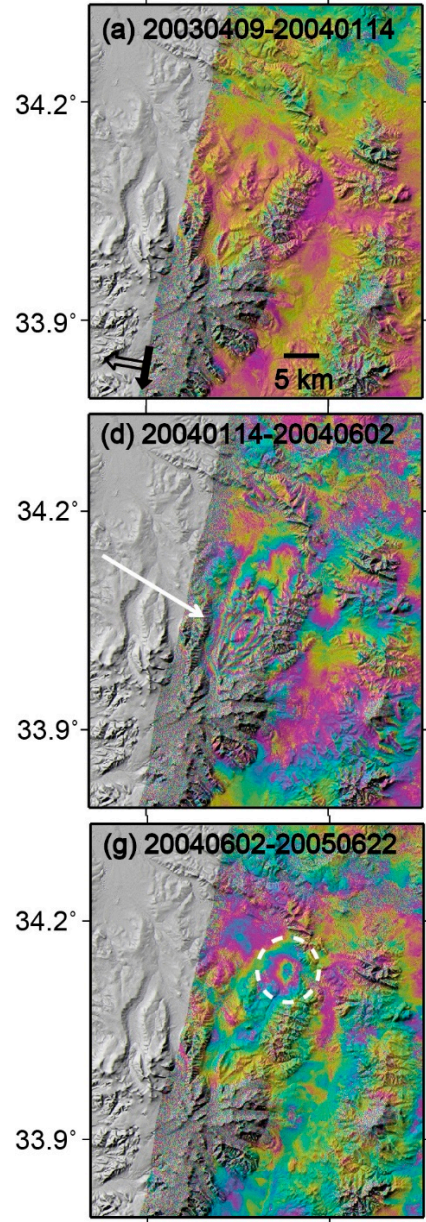

$89.1^{\circ}$
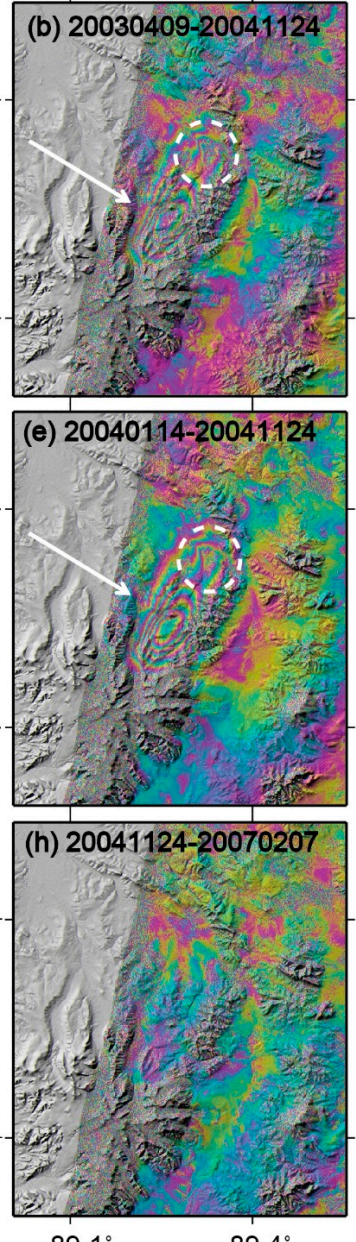
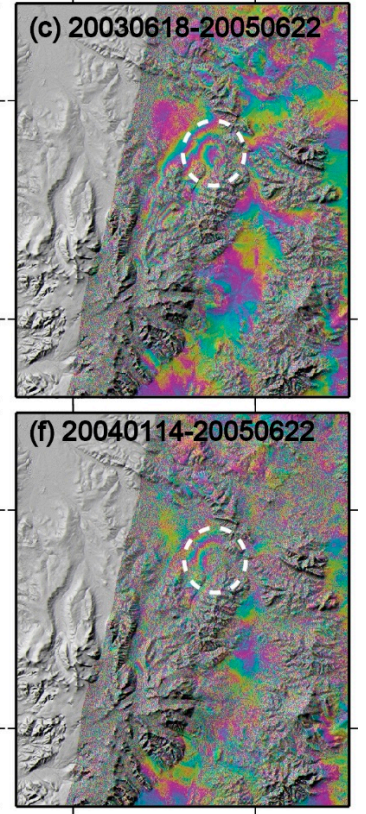

$89.1^{\circ}$

$89.4^{\circ}$

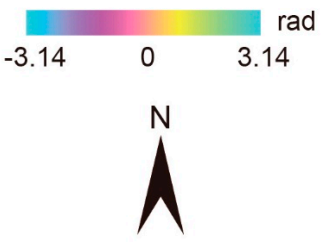

Figure 4. Interferograms related to the 2004 earthquakes. Location of the interferograms is shown in Figure 1 as a dashed box. Start and end dates are provided above each image using the format yyyymmdd. White solid arrows point to the oval pattern caused by the 27 March 2004 event, whereas the white dashed circles delineate the circular pattern caused by the 3 July 2004 event. Satellite flight direction and radar look direction are labeled as short solid arrow and open arrow, respectively. Each fringe, i.e., full color cycle from red through yellow to blue, represents $28 \mathrm{~mm}$ of range increase between the ground and satellite. (a) 20030409-20040114; (b) 20030409-20041124; (c) 20030618-20050622; (d) 20040114-20040622; (e) 20040114-20041124; (f) 20040114-20050622; (g) 20040602-20050622; (h) 20041124-20070207.

\subsection{The 2004 Earthquakes}

Figure 4 shows interferograms related to the 2004 earthquakes. Before 14 January 2004 and after 24 November 2004, no obvious deformation is detected in the corresponding interferograms (Figure 4a,h). In addition, similar to the analysis of the 7 July 2003 event, we confirm that the large-scale oval pattern signal that elongated NE-SW, as shown in Figure 4b-e, was primarily caused by the 2004 earthquakes. The oval signal shows approximately five red-yellow-blue color cycles, indicating a negative displacement reaching up to $14 \mathrm{~cm}$. However, we note another small-scale circular signal that persisted in several interferograms (Figure $4 \mathrm{~b}, \mathrm{c}, \mathrm{e}-\mathrm{g}$ ), located northeast of the oval. The oval fringes and the circular fringes partially overlap. However, the signal is not detected before 2 June 2004 (Figure 4d). Referring to the catalogue (Table 1), we infer that the local small-scale subsidence signal may be caused by the earthquake that occurred on 3 July 2004. 


\section{Source Modeling and Analysis}

Using the InSAR surface displacements, we can potentially place constraints on the fault orientation according to the depth and the spatial extent through modeling. To consider the high spatial correlation of pixels and expedite the modeling process, we first attempt to down-sample the InSAR data using the quadtree method (e.g., [20]). However, this fails to capture the main deformation pattern with a high enough resolution. Then, we sample the near-field area at a dense regular spacing grid and the far-field area at a sparse regular spacing grid. The modeling is executed in two steps. First, we perform an exhaustive search for the best-fit fault parameters assuming uniform slip. Then, we divide the faults into sub-faults and estimate the slip on each patch.

\subsection{Uniform Slip Model}

\subsubsection{The 7 July 2003 Event}

We choose Figure $3 \mathrm{~b}$ for modeling because it has a shorter time interval than Figure 3a, containing less possible pre- and post-seismic deformation. Qualitatively, the coseismic deformation pattern shown in Figure 3 is consistent with a NW-SE fault plane for the 7 July 2003 earthquake. However, because all of the available interferograms are in the same viewing geometry, we cannot easily identify the hanging wall of the causative fault. Therefore, we perform two inversions on the $7 \mathrm{July}$ 2003 earthquake. The first model constrains the strike to be within $270^{\circ}$ and $360^{\circ}$, and the second model constrains the strike to be within $90^{\circ}$ and $180^{\circ}$. The first model produces a solution with an approximately horizontal fault plane, which is inconsistent with the deformation pattern and is physically unrealistic for a causative fault. Hence, we consider the first model to be unlikely. In contrast, the second model achieves reasonable fault parameters. Referring to the pattern of the observed deformation, we assume that the causative fault could be interpreted as a single rectangular plane with a uniform slip embedded in a homogeneous, isotropic, elastic half-space [21]. Nine parameters define the rectangular dislocation: length, width, depth, strike, dip, slip magnitude (dipand strike-slip along the fault), and location (two parameters). In the model, we introduce linear terms to account for any possible phase ramp due to uncertainties in satellite positions [5]. We use the downhill simplex method and Monte Carlo simulations [22] to estimate the optimal parameters and their uncertainties, and the root mean square errors (RMSE) between the observed and modeled interferograms as the prediction-fit criterion. We randomly choose the starting parameters within broad bounds to generate 1000 uniformly distributed samples. For each of the nine parameters in the inversion, the histogram of the set of best-fit solution parameters is a Gaussian from which we select the mean value as the optimal solution and estimate the standard deviation. Figure 5a shows the distributions of the solution parameters, indicating they are well retrieved.

Figure 6 shows the observed (a), modeled (b), and residual (c) interferograms of the model. The model fits the observed interferogram reasonably well. The displacement profile in Figure $6 \mathrm{~d}-\mathrm{f}$ does not show a discontinuity, implying that the fault does not break the surface. Table 2 shows the optimal parameters of the best-fit fault. All of the model parameters are well constrained according to their uncertainties (Table 2). We attribute the goodness of fit to the reasonably good coherence of the observed interferogram. The causative fault is located at a depth of $5 \mathrm{~km}$, dipping $80^{\circ}$ to the northeast. The slip is a dominantly dip slip, with a small amount of dextral slip. In other words, the 7 July 2003 earthquake is supposed to be a normal-faulting event with a right-lateral slip component. This focal mechanism is consistent with that in the NEIC's catalogue, but different with from that in the GCMT's catalogue (Figure 1). 

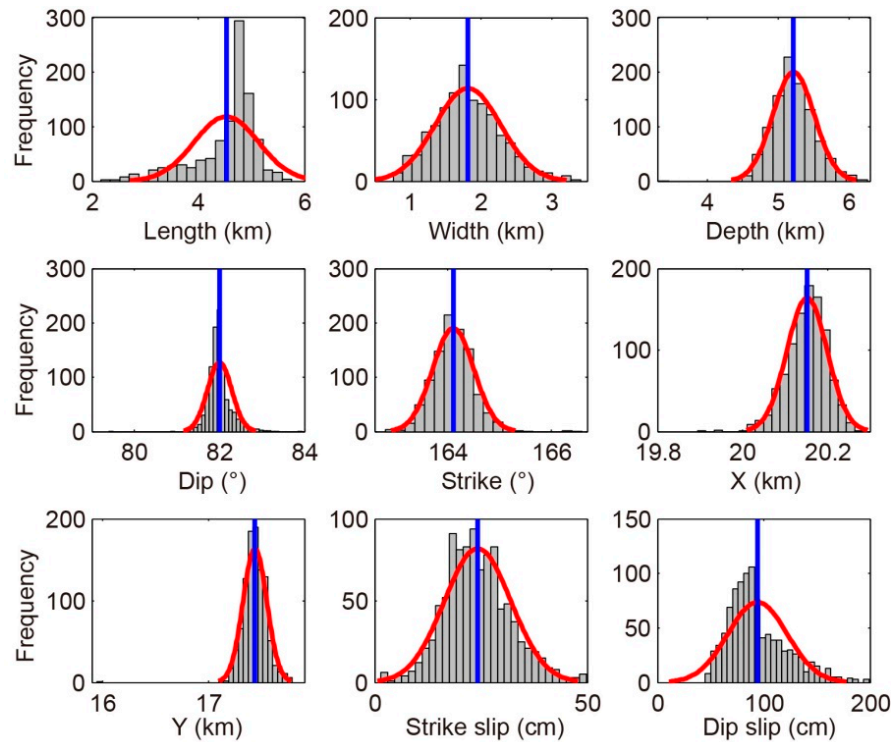

(a)
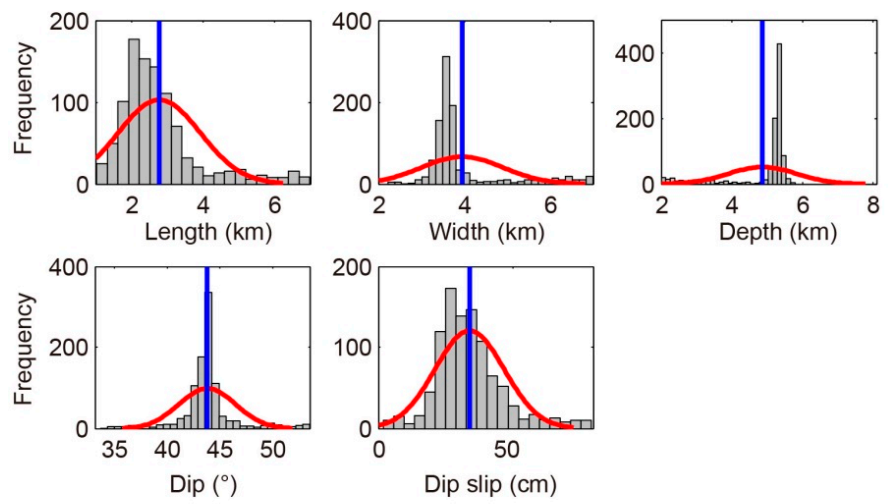

(b)
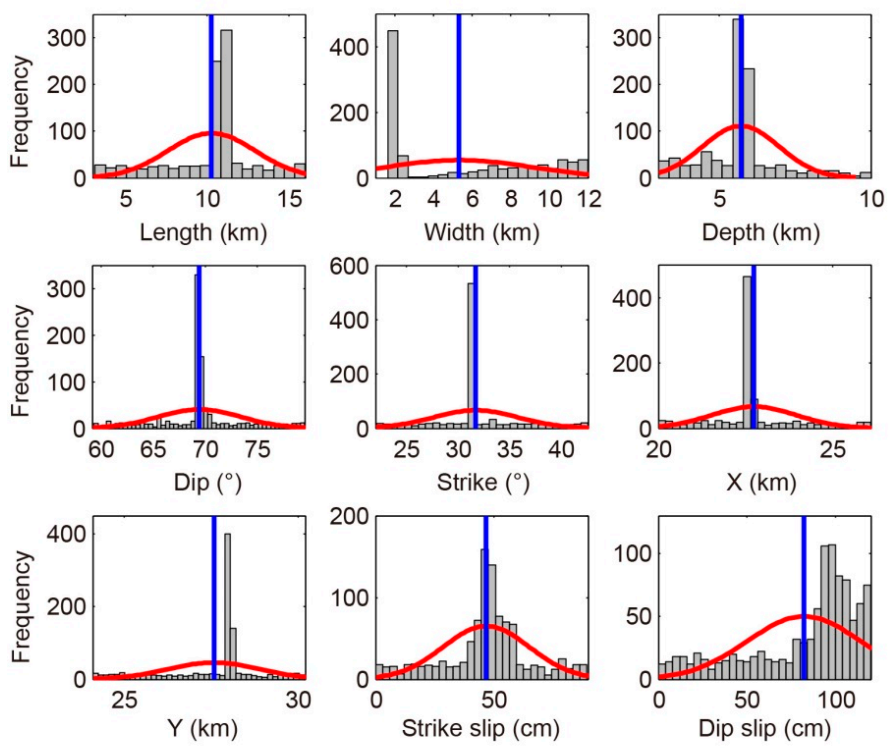

(c)

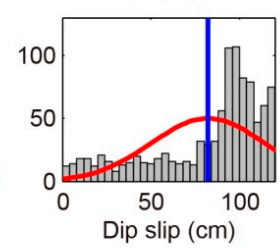

Figure 5. Frequency histograms of modelled parameters determined from 1000 independent runs of the inversion algorithm. Histograms represent the 1000 best-fit solution parameters (black bins) obtained from inversions of InSAR coseismic deformation maps. The optimal solution for the parameters is estimated from the mean value (blue vertical line) of the best-fit Gaussian (red curve). (a) 7 July 2003 earthquake; (b) 3 July 2004 earthquake; (c) 27 March 2004 earthquake. 

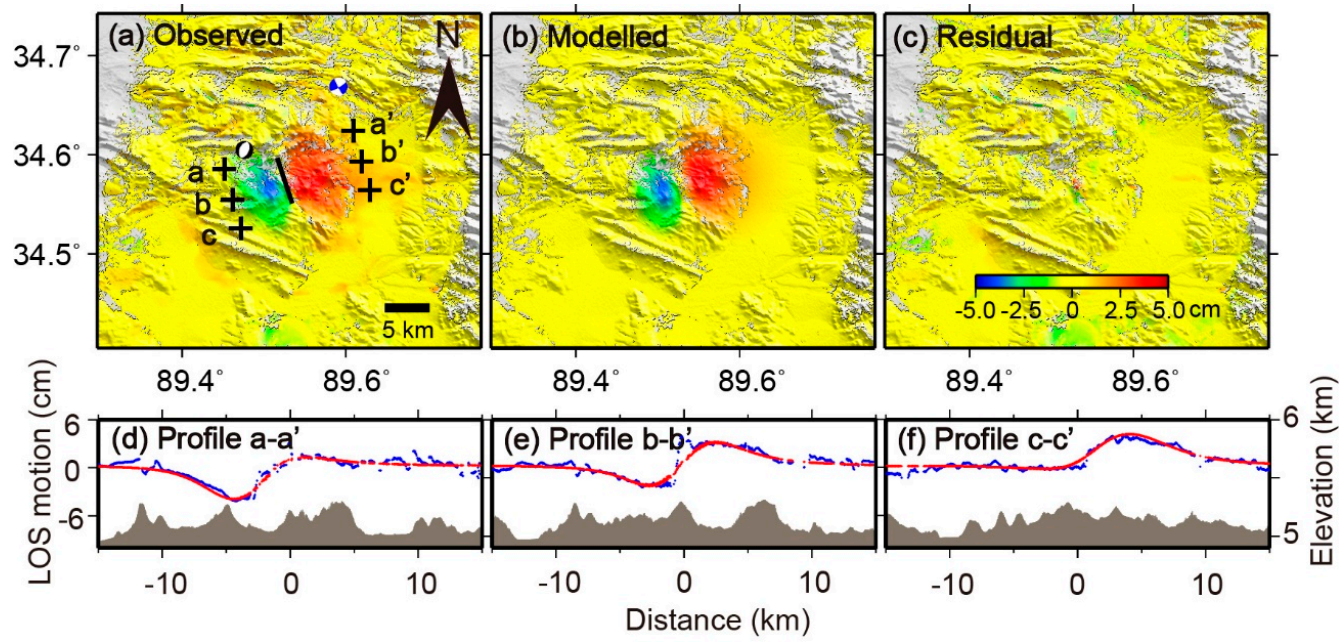

Figure 6. Coseismic deformation (range displacement-negative away from the satellite) and model for uniform slip inversion of the 7 July 2003 earthquake. (a) Observed interferogram spanning 20030618-20030723. Black and blue beach balls show focal mechanisms of NEIC and GCMT catalogues, respectively; (b) Synthetic interferogram for a uniform slip elastic dislocation model; (c) Residual interferogram, which is the difference between observed (a) and modeled (b) interferograms; (d,e,f) are profiles of line-of-sight (LOS) displacements (blue dots), model LOS displacements (red dots) and topography (grey), respectively. Crosses in (a) indicate profile locations. Black line in (a) represents the modeled fault trace.

Table 2. Source fault parameters and their $2 \sigma$ uncertainties of the 7 July 2003 earthquake.

\begin{tabular}{cc}
\hline Parameter (Unit) & 20030707 Ms 6.0 \\
\hline Length $(\mathrm{km})$ & $4.5 \pm 0.5$ \\
Width $(\mathrm{km})$ & $1.8 \pm 0.6$ \\
Depth $(\mathrm{km})$ & $5.2 \pm 0.4$ \\
Strike $\left(^{\circ}\right)$ & $164.0 \pm 0.5$ \\
Dip $\left(^{\circ}\right)$ & $81.9 \pm 0.5$ \\
Strike slip $(\mathrm{cm})$ & $25.1 \pm 11.0$ \\
Dip slip $(\mathrm{cm})$ & $88.0 \pm 20.0$ \\
Longitude $^{1}\left(^{\circ}\right)$ & $89.5239 \pm 0.001$ \\
Latitude $^{1}\left(^{\circ}\right)$ & $34.5901 \pm 0.001$
\end{tabular}

${ }^{1}$ The latitude/longitude location is the top left corner of the modeled fault projected to the surface.

\subsubsection{The 2004 Earthquakes}

Based on the analysis in Section 2.2, we infer that the observed large-scale oval signal and the small circular pattern were created by two separate earthquakes, probably occurring on separate faults. In other words, we assume that the 27 March 2004 Ms 6.2 earthquake produced the oval pattern displacement and the 3 July event with Ms 5.1 was related to the small circular displacement. To determine the two sources of observed displacements, we employ the following modeling strategy. We choose Figure 4e,g for modeling because they have the best coherence and least apparent atmospheric contaminations. First, we model Figure $4 \mathrm{~g}$ to determine the fault parameters of the $3 \mathrm{July}$ event because it only includes deformation caused by that event (Figures 4 and 6b; Table 3). Because only a single lobe is shown in the interferogram, we fix the location of the presumed fault during modeling (Figure 7a; Table 3). The deformation fringes shown in Figure 7a change gradually from maximum subsidence to zero toward the west, whereas the fringes change suddenly to zero toward the east. This deformation pattern supports a west dipping normal fault. Therefore, we fix the strike of the model fault to 
be approximately $\mathrm{N}-\mathrm{S}$ and constrain the rake angle to a purely normal faulting mechanism. Then, we remove Figure $7 \mathrm{~b}$ from Figure $4 \mathrm{e}$, and model the residual interferogram to estimate the source of the 27 March event (Figures $6 \mathrm{c}$ and 8; Table 3). Figure 8 shows the modeling result. The model fault produces a first order fit to the observed deformation pattern. The northern remaining signal in the residual interferogram is most probably due to atmospheric artifacts. The near-fault fringes of the 3 July 2004 event are unmodeled due to a simple uniform slip elastic dislocation model (Figure 7d), which has also been evidenced by several previous InSAR studies (e.g., [23,24]). The best-fitting model for the 27 March 2004 Ms 6.2 earthquake indicates a normal fault striking southwest-northeast, dipping to the southeast with a moderately oblique right-lateral slip. This mechanism is consistent with the NEIC and GCMT catalogues (Figure 1). The 3 July Ms 5.1 earthquake was caused by a normal fault, which is consistent with the GCMT's catalogue (Figure 1).

Table 3. Source fault parameters and their $2 \sigma$ uncertainties of the 27 March 2004 Ms 6.2 and 3 July Ms 5.1 earthquakes.

\begin{tabular}{ccc}
\hline Parameter (Unit) & 20040327 Ms 6.2 & 20040703 Ms 5.1 \\
\hline Length $(\mathrm{km})$ & $10.2 \pm 2.1$ & $2.8 \pm 1.1$ \\
Width $(\mathrm{km})$ & $5.3 \pm 2.9$ & $3.9 \pm 0.8$ \\
Depth $(\mathrm{km})$ & $5.7 \pm 0.8$ & $4.9 \pm 0.9$ \\
Strike $\left(^{\circ}\right)$ & $31.7 \pm 2.1$ & $182.3^{*}$ \\
Dip $\left(^{\circ}\right)$ & $69.4 \pm 3.9$ & $43.8 \pm 2.2$ \\
Strike slip $(\mathrm{cm})$ & $46.8 \pm 14.0$ & $0.0^{*}$ \\
Dip slip $(\mathrm{cm})$ & $82.1 \pm 21.0$ & $34.0 \pm 10.0$ \\
Longitude $\left(^{\circ}\right)$ & $89.2004 \pm 0.01^{1}$ & $89.3613^{1, *}$ \\
Latitude $\left(^{\circ}\right)$ & $34.0157 \pm 0.01^{1}$ & $34.1443^{1, *}$
\end{tabular}

${ }^{1}$ The latitude/longitude locations are the top left corner of the modeled faults projected to the surface; ${ }^{*}$ The parameters denoted by an asterisk are fixed in modeling.
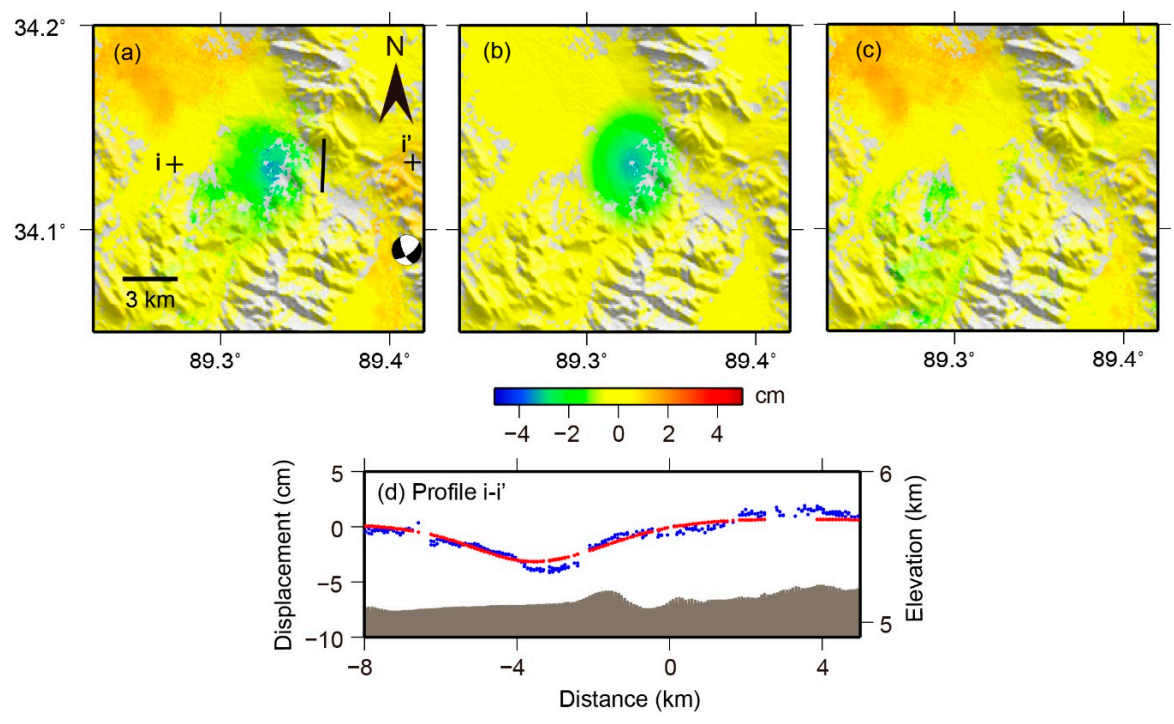

Figure 7. Coseismic deformation (range displacement-negative away from the satellite) and model for uniform slip inversion of the 3 July 2004 earthquake. Location of the interferograms is shown in Figure 1 as a green box. (a) Observed interferogram spanning 20040602-20050622. Focal mechanism from GCMT catalogue is shown; (b) Synthetic interferogram for a uniform slip elastic dislocation model; (c) Residual interferogram, which is the difference between observed (a) and modeled (b) interferograms; (d) Profile of line-of-sight (LOS) displacements (blue dots), model LOS displacements (red dots) and topography (grey). Crosses in (a) indicate profile locations. Black lines in (a) represent modeled fault trace. 

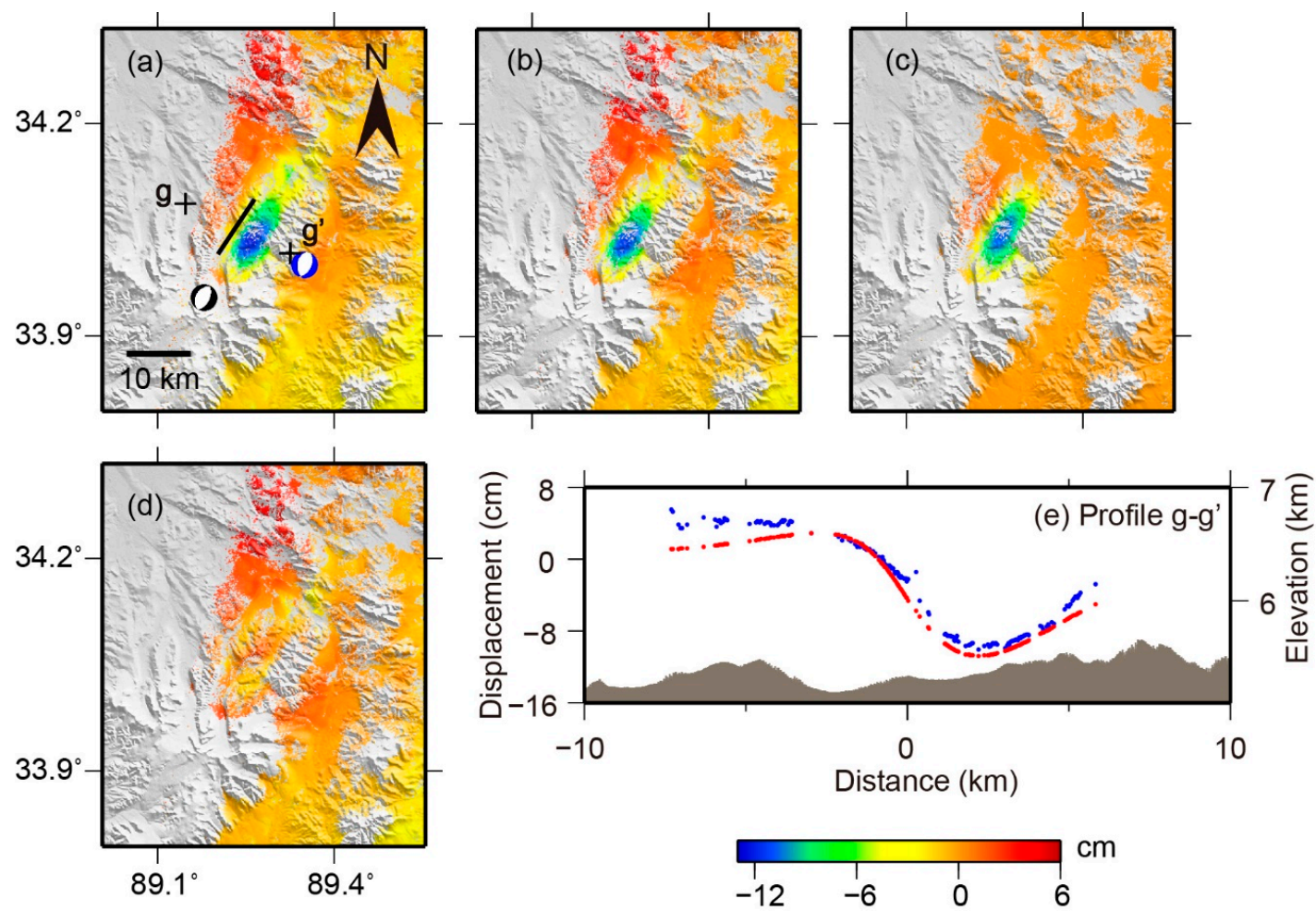

Figure 8. Coseismic deformation (range displacement-negative away from the satellite) and model for uniform slip inversion of the 27 March 2004 earthquake. (a) Observed interferogram spanning 20040114-20041124. Black and blue beach balls show focal mechanisms from NEIC and GCMT catalogues, respectively; (b) Observed interferogram spanning 20040114-20041124 obtained by subtracting Figure 7b; (c) Synthetic interferogram for uniform slip elastic dislocation model; (d) Residual interferogram, which is the difference between observed (b) and modeled (c) interferograms; (e) Profile of line-of-sight (LOS) displacements (blue dots), model LOS displacements (red dots), and topography (grey). Crosses in (a) indicate profile locations. Black line in (a) represents modeled fault trace.

\subsection{Distributed Slip Model}

Although uniform slip models can provide a reasonable fit to the data, we know that a homogeneous slip on a sharply bounded fault plane is not physically reasonable. Moreover, the simple uniform slip dislocation lacks the capability to model near-fault processes of the 3 July 2004 event (Figure 7d). Thus, we obtain more realistic models by discretizing the fault planes into sub-faults and solve for the slip on each patch, thereby allowing the slip to smoothly taper to zero towards the edges of the fault plane. We use the inversion code SDM [25] based on the constrained least-squares method, which has been used in a number of recent publications for analyzing GPS and InSAR coseismic deformation data (e.g., [26-29]). To overcome the problem of the non-uniqueness and instability of the inversion result, a smoothing constraint is applied to the slip distribution. An optimal smoothing factor is determined by analyzing the trade-off curve between the data misfit and slip roughness (Figure 9).

\subsubsection{The 7 July 2003 Event}

Using the fault geometry determined in the uniform slip modeling, we extend the fault plane along the strike and down-dip by increasing its total length to $17 \mathrm{~km}$ and its down-dip width to $10 \mathrm{~km}$. The fault is discretized into patches that are $1 \mathrm{~km}$ in both the along-strike and down-dip directions. Then, the slip on all of the small patches is estimated using the SDM code [25]. Figure 10 shows the 
modeling result. Compared to the uniform slip dislocation modeling result (Figure 6), the modeling result shows a slight improvement in the near fault fit (Figure 10). The correlation coefficient between the observation and prediction is $97.2 \%$. However, the results are not substantially improved from the uniform to the distributed slip model. The calculated slip distribution is shown in Figure 11. Most of the slip occurs at depths of 3 to $9 \mathrm{~km}$, with a maximum slip of approximately $24 \mathrm{~cm}$ at a depth of $6 \mathrm{~km}$. The geodetic moment based on the distributed slip is $2.19 \times 10^{17} \mathrm{Nm}$, corresponding to Mw 5.56, which is comparable to the seismological estimates ranging from Mw 5.5 (from NEIC) to Mw 5.8 (from GCMT) (Figure 1). Error analysis shows that the maximum standard deviation is approximately $1.5 \mathrm{~cm}$, indicating the slip is well retrieved (Figure 10c).
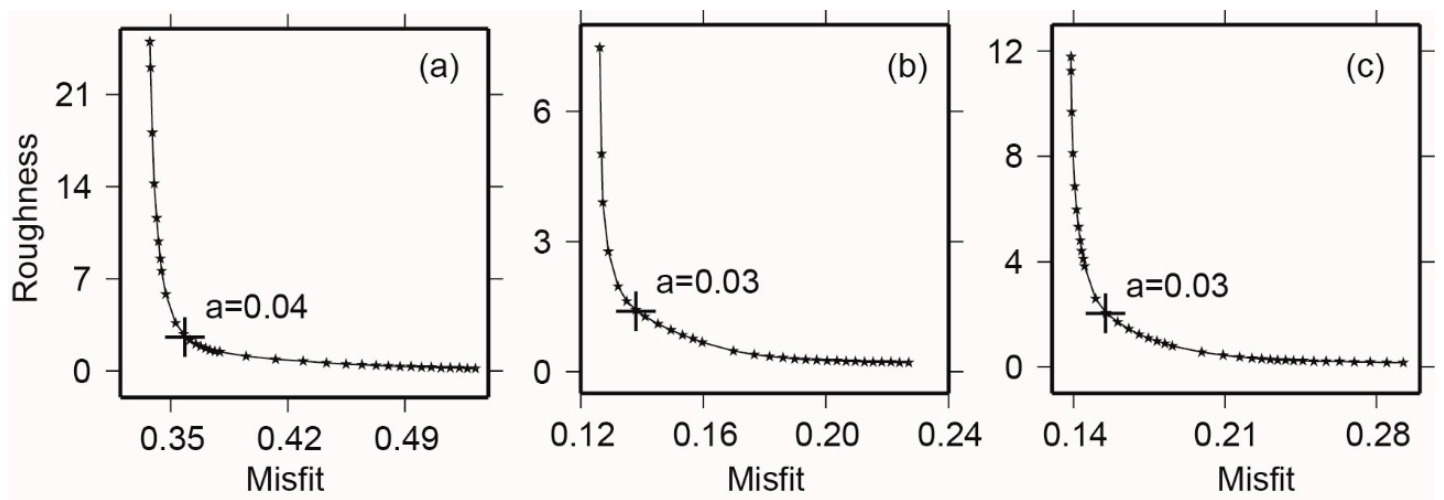

Figure 9. Trade-off curves between misfit and model roughness. The roughness is the normalized value. Pluses indicate locations of optimal smoothing parameters where balances between model misfit and smoothness is achieved. (a) 7 July 2003 earthquake; (b) 3 July 2004 earthquake; (c) 27 March 2004 earthquake.

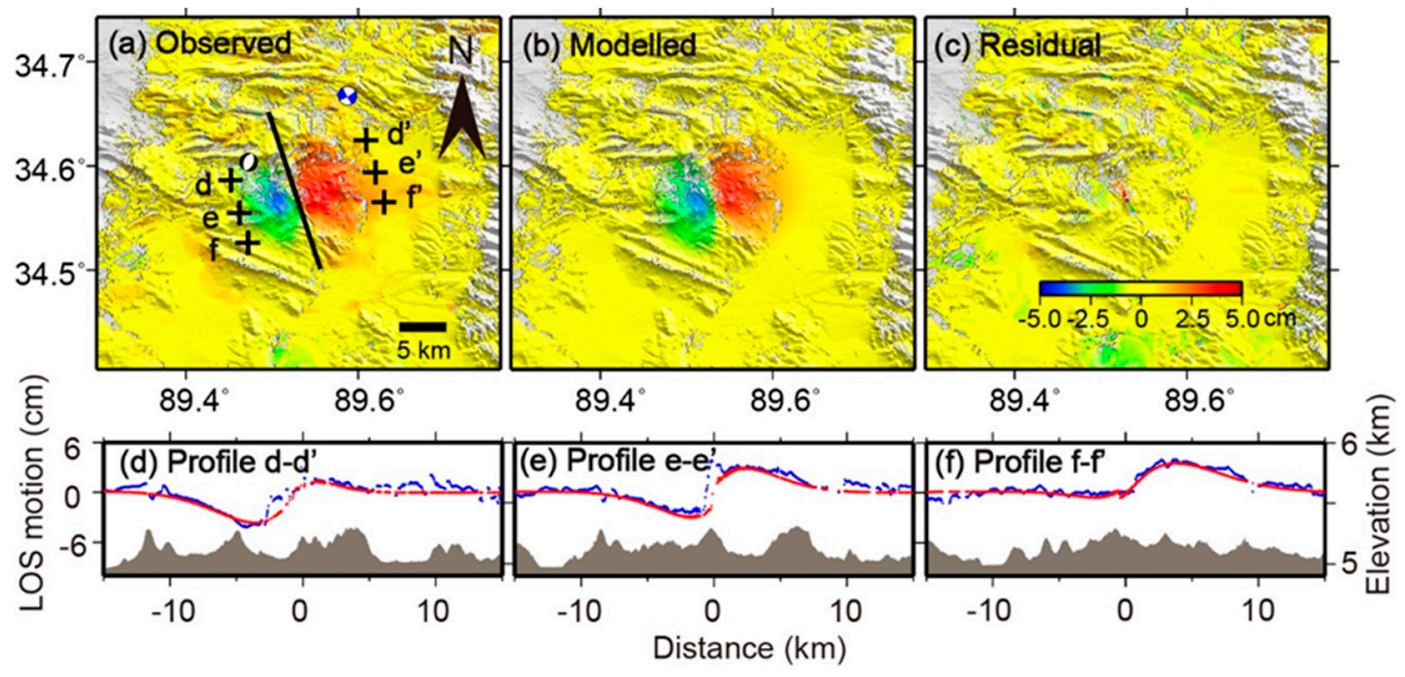

Figure 10. Coseismic deformation (range displacement-negative away from the satellite) and model for distributed slip inversion for the 7 July 2003 earthquake. (a) Observed interferogram spanning 20030618-20030723. Black and blue beach balls show focal mechanisms from NEIC and GCMT catalogues, respectively; (b) Synthetic interferogram and (c) residual interferogram based upon the fault plane (black line in (a)) slip distribution shown in Figure 11; (d,e,f) are profiles of line-of-sight (LOS) displacements (blue dots), model LOS displacements (red dots), and topography (grey), respectively. Crosses in (a) indicate profile locations. 


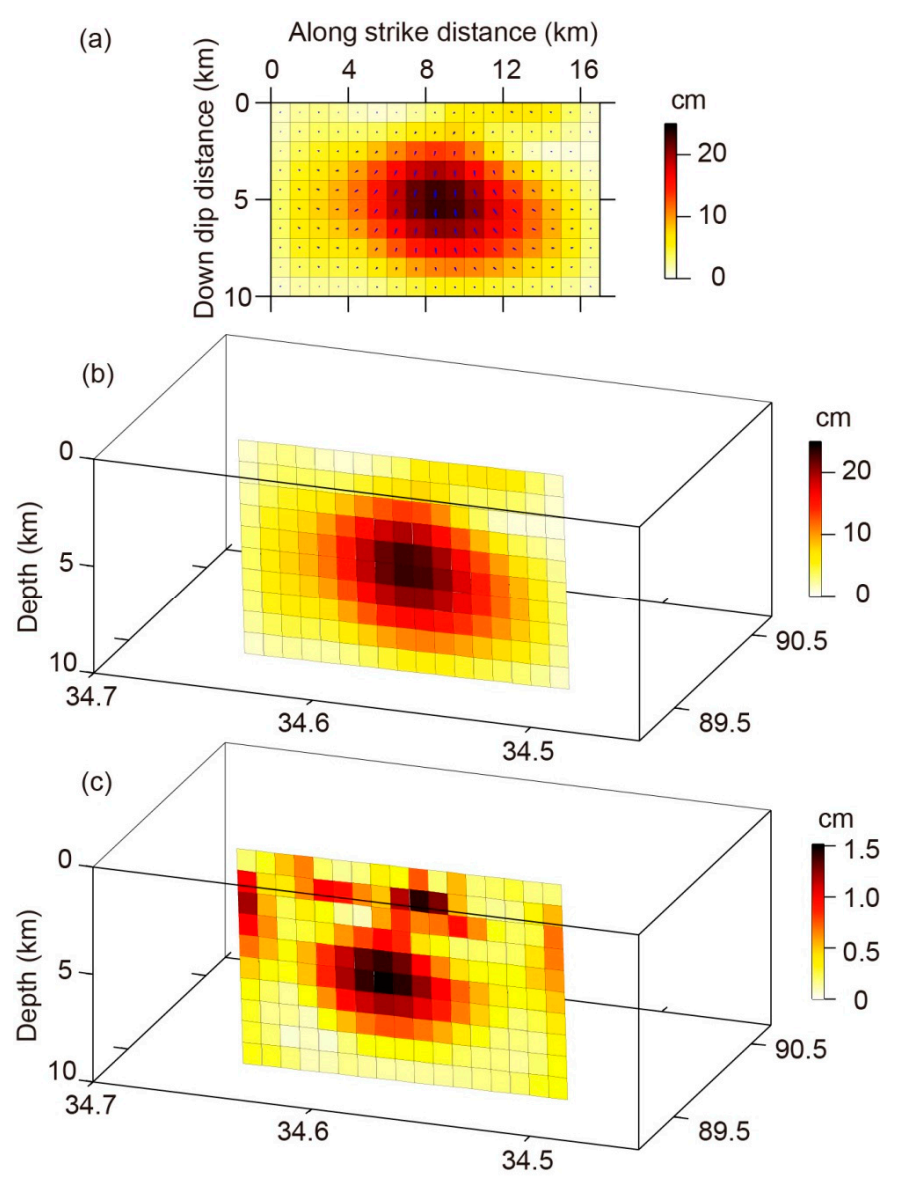

Figure 11. Slip distributions for modeled seismic source of the 7 July 2003 event. (a) Perpendicular view of the fault, with slip vectors plotted in addition to the slip magnitudes shown in color; (b) 3-D view from WSW; (c) $1 \sigma$ uncertainty for slip distribution as shown in (a) and (b), estimated from performing 100 inversions.

\subsubsection{The 2004 Earthquakes}

Similar to the procedure described in Section 3.2.1, we use the fault geometry of the parameters from the best-fitting uniform-slip model (Table 3) and estimate the slip distribution for the 2004 earthquakes. Figure 12 shows the modeling result of the 7 July event. Compared to the uniform slip dislocation modeling result (Figure 7d), the modeling result based on distributed-slip model shows a significant improvement in the near fault fit (Figure 12d). The correlation coefficient between the observation and prediction is $98.9 \%$. The calculated slip distributions are shown in Figure 13. Figure 13 shows that most of the slip occurs at depths of 4 to $9 \mathrm{~km}$, with a maximum slip of approximately $14 \mathrm{~cm}$ at a depth of $7 \mathrm{~km}$. The geodetic moment is $1.11 \times 10^{17} \mathrm{Nm}$, resulting in a $\mathrm{Mw}$ of 5.33 . Figure $13 \mathrm{c}$ shows small slip uncertainties on the fault, demonstrating that the slip distributions shown in Figure 13a,b are reliable. Figure 14 shows the modeling result of the 27 March 2004 Ms 6.2 event, showing improvement compared to the uniform slip model. Figure 15 shows the slip distribution. The coseismic slip is concentrated at depths of 1 to $6 \mathrm{~km}$, with a maximum slip of approximately $55 \mathrm{~cm}$ at a depth of $4 \mathrm{~km}$. The geodetic moment is $6.92 \times 10^{17} \mathrm{Nm}$, resulting in a Mw of 5.86, which is slightly lower than the seismological estimates, that is, Mw 6.0 (from NEIC and GCMT) (Figure 1). Error analysis shows that the maximum standard deviation is approximately $7 \mathrm{~cm}$, on the southern part (Figure 15c). Slip on the central part (where major slip occurs) is well retrieved, with the $1 \sigma$ uncertainty generally $\leqslant 4 \mathrm{~cm}$. 

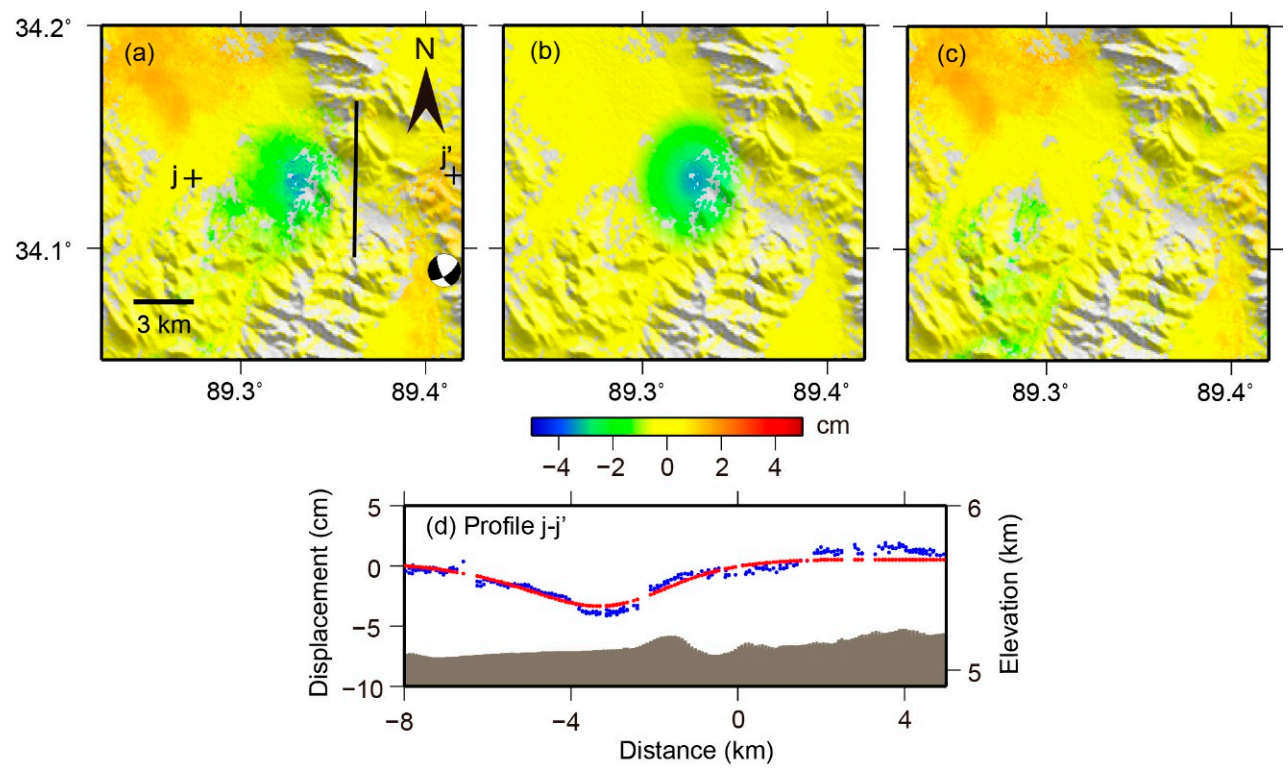

Figure 12. Coseismic deformation (range displacement-negative away from the satellite) and model for distributed slip inversion of the 3 July 2004 earthquake. (a) Observed interferogram spanning 20040602-20050622. Focal mechanism from GCMT catalogue is shown; (b) Synthetic interferogram and (c) residual interferogram based upon the fault plane' (black line in (a)) slip distribution shown in Figure 13; (d) Profile of line-of-sight (LOS) displacements (blue dots), model LOS displacements (red dots), and topography (grey). Crosses in (a) indicate profile locations.

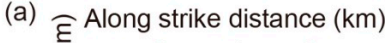

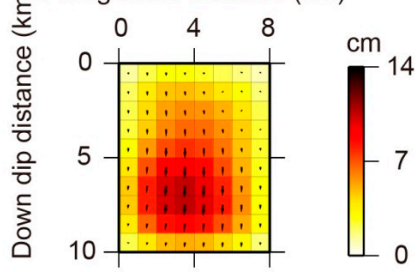

(b)
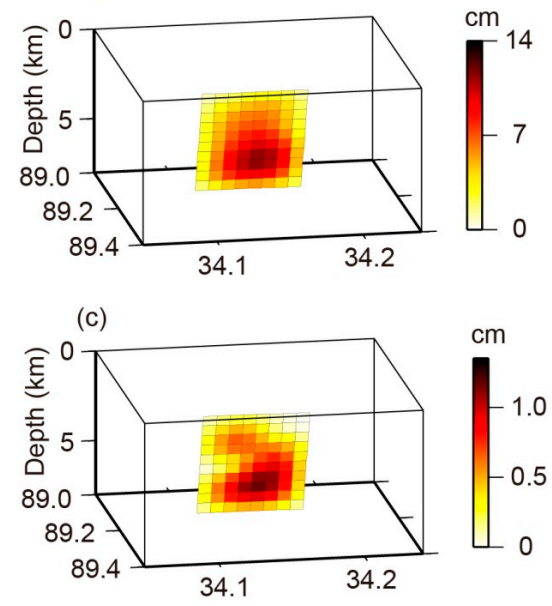

Figure 13. Slip distributions for the modeled seismic sources of the 3 July 2004 event. (a) Perpendicular view of the fault, with slip vectors plotted in addition to the slip magnitudes shown in color; (b) 3-D view from ENE; (c) $1 \sigma$ uncertainty for the slip distribution as shown in (a,b), estimated from performing 100 inversions. 


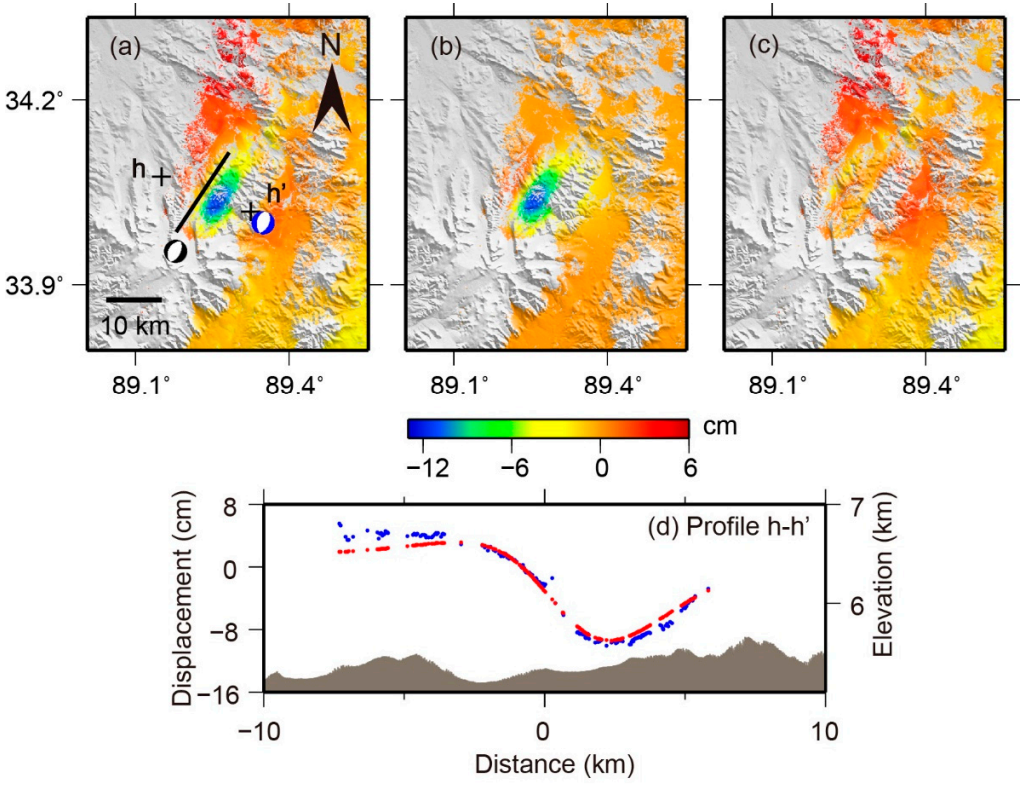

Figure 14. Coseismic deformation (range displacement-negative away from the satellite) and model for distributed slip inversion of the 27 March 2004 earthquake. (a) Observed interferogram spanning 20040114-20041124 obtained by subtracting Figure 4g. Black and blue beach balls show focal mechanisms from NEIC and GCMT catalogues, respectively; (b) Synthetic interferogram and (c) residual interferogram based upon the fault plane's (black line in (a)) slip distribution shown in Figure 15; (d) Profile of the line-of-sight (LOS) displacements (blue dots), model LOS displacements (red dots), and topography (grey). Crosses in (a) indicate profile locations.
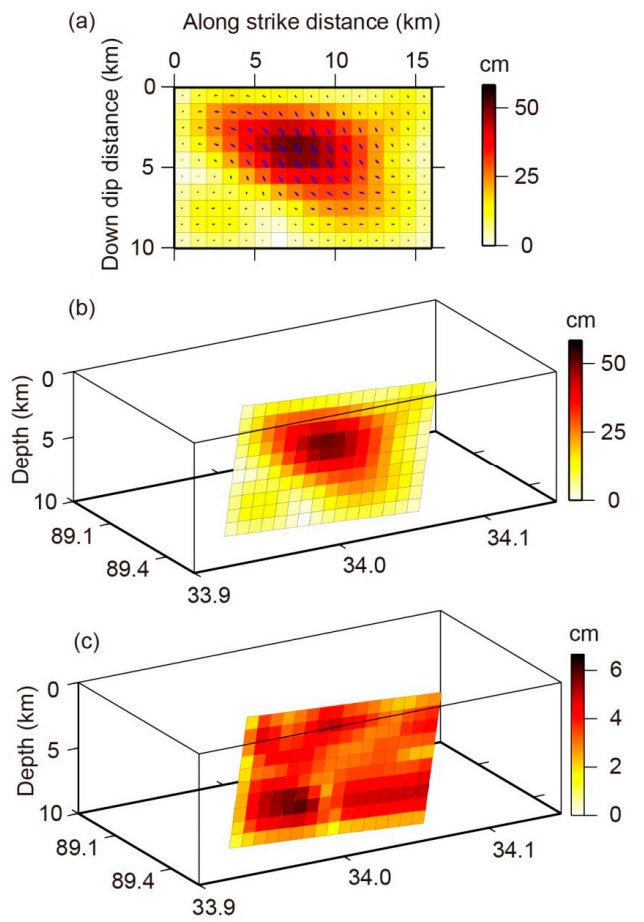

Figure 15. Slip distribution for modeled seismic source of the 27 March 2004 event. (a) Perpendicular view of the fault, with slip vectors plotted in addition to the slip magnitudes shown in color; (b) 3-D view from WSE; (c) $1 \sigma$ uncertainty for the slip distribution as shown in $(\mathbf{a}, \mathbf{b})$, estimated from performing 100 inversions. 


\section{Discussion}

\subsection{Static Stress Drop}

The static stress drop provides hints on the scaling of the static parameters (such as the source size or final displacement) characterizing an earthquake [30]. In this study, we evaluate the static stress drop of the 2003-2004 Bange earthquake sequence using the relationship [31-33]:

$$
\Delta \sigma=7 \times M_{0} / 16 / r^{3}
$$

where $M_{0}$ is the seismic moment and $r$ is the source radius. This relationship assumes a circular rupture, and the parameter $\mathrm{r}$ was modeled as $r=\operatorname{sqrt}(L W / \pi)$, where $L$ and $W$ are the rupture length and width, respectively.

Table 4 provides the calculated stress drop for the best-fitting uniform slip model. The average stress drops of the 2003 and 2004 earthquakes are approximately 19, 13, and $6 \mathrm{Mpa}$, which are consistent with the stress drops of moderate earthquakes that occur in the Tibetan Plateau (e.g., [34]). Though the stress drops are larger than the median of an intraplate earthquake's stress drop of $5.95 \mathrm{MPa}$ [33], they fall within the typical range of 0.3 to $50 \mathrm{MPa}$ [33].

Table 4. Average static stress drop for the 2003-2004 earthquake sequence inferred from InSAR observations.

\begin{tabular}{cccc}
\hline Earthquake & Seismic Moment $\left(\mathbf{N m} \times \mathbf{1 0}^{\mathbf{1 7}}\right)^{\mathbf{1}}$ & Inferred Source Radius $(\mathbf{m})$ & Stress Drop (MPa) \\
\hline 20030707 Ms 6.0 & 2.35 & 1748 & 19.2 \\
20040327 Ms 6.2 & 7.11 & 2891 & 12.9 \\
20040703 Ms 5.1 & 4.19 & 3116 & 6.1 \\
\hline
\end{tabular}

${ }^{1}$ The adopted shear modulus $\mu$ was $30 \mathrm{GPa}$.

\subsection{Coulomb Stress Change Analysis}

To test whether more recent earthquakes in the Bange earthquake sequence may have been triggered by previous ones, we calculate the progression of the Coulomb stress changes by using the PSGRN/PSCMP code based on the distributed slip source [35] (e.g., [36]). First, we calculate the static Coulomb stress change induced by the 7 July 2003 event on the fault plane of the 27 March 2004 event (Figure 16a). Then, the joint effect of the first two large events (i.e., the 7 July 2003 event and 27 March 2004 event) on the July 32004 event is calculated (Figure 16b). The Coulomb failure criterion used is [37]:

$$
\Delta \mathrm{CFF}=\Delta \tau+\mu^{\prime} \times \Delta \sigma_{\mathrm{n}}
$$

where $\Delta$ CFF is the Coulomb stress change, $\Delta \tau$ is the change in shear stress on the receiver fault (positive in the slip direction), $\mu^{\prime}$ is the apparent coefficient of friction and $\Delta \sigma_{\mathrm{n}}$ is the change in normal stress acting on the receiver fault (with extension positive). The value $\mu^{\prime}$ is treated as a constant with a value of 0.4 [38]. A positive $\triangle \mathrm{CFF}$ implies that the effect of previous events advanced subsequent shocks toward failure, whereas a negative $\triangle \mathrm{CFF}$ represents stress release and a delayed failure time.

Figure 16a shows that the stress change induced by the 7 July 2003 event on the fault plane of the 27 March 2004 event is around $0 \mathrm{MPa}$. The low stress change indicates the 27 March 2004 event may not be enhanced by the 7 July 2003 event, possibly because of the long distance (approximately $70 \mathrm{~km}$ ) between these two earthquakes. The effect of the 7 July 2003 and 27 March 2004 events on the July 32004 event is positive on most part of the fault (Figure 16b), indicating that the receiver fault are brought closer to failure (e.g., [39,40]). Therefore, the 3 July 2004 event is positively triggered by the 7 July 2003 and 27 March 2004 events. 


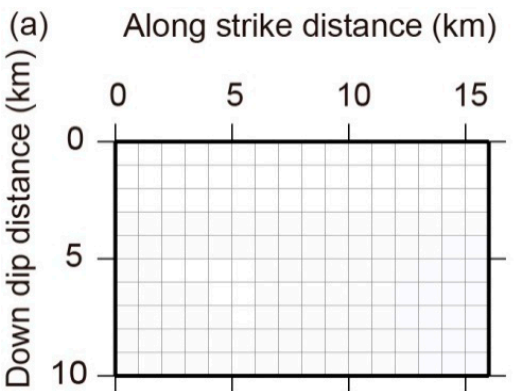

(b) Along strike distance $(\mathrm{km})$

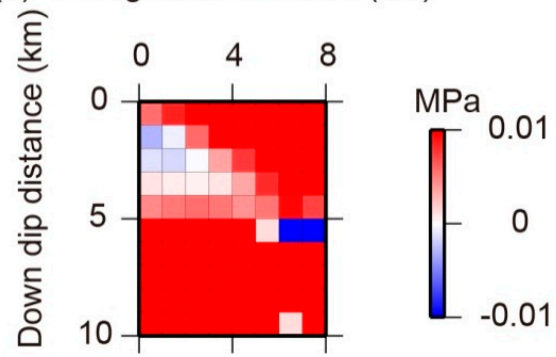

Figure 16. (a) Coseismic Coulomb stress change on the fault plane of the 27 March 2004 event triggered by the 7 July 2003 event; (b) Stress change induced on the 3 July 2004 earthquake triggered by 7 July 2003 and 27 March 2004 events.

\subsection{Normal Faulting Earthquakes in Tibetan Plateau}

Figure 17 indicates that moderate-sized ( $\mathrm{Mw}$ 5.5-7.0) normal faulting earthquakes are common in the Tibetan Plateau. For instance, the 2008 Yutian earthquake in the northwest part of the plateau [41,42] was the largest normal faulting earthquake ever recorded instrumentally in northern Tibet. Elliott et al. [41] studied a series of eight Mw 5.9-7.1 normal faulting earthquakes and inferred that the extension of the Tibetan Plateau is driven primarily by gravitational forces. Ryder et al. [34] took the 2004-2008 Zhongba earthquake sequence as an example, and studied an extensional earthquake sequence that occurred on the Tibetan Plateau.

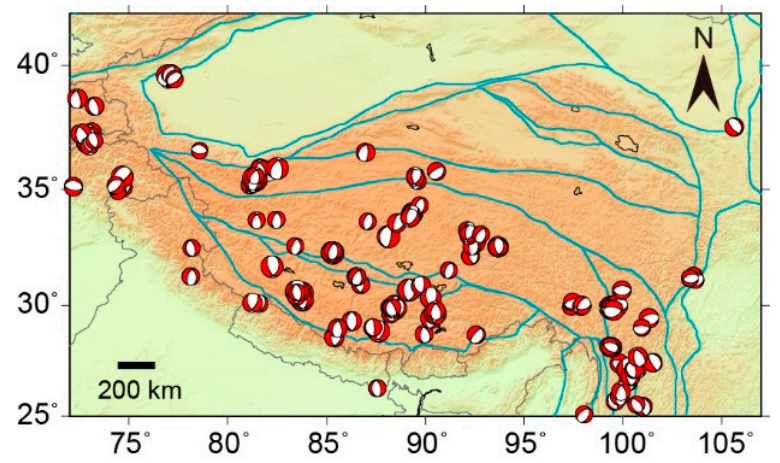

Figure 17. Normal faulting earthquakes with $\mathrm{Mw} \geqslant 5.5$ in Tibetan Plateau (1976-2015). Focal mechanisms are based on GCMT catalogue.

Tectonically, east-west extension in the central Tibetan Plateau is accommodated by normal faults and rift systems that trend north-south (e.g., [2,43]), which are active structures that rupture in some normal faulting earthquakes. Therefore, moderate-sized normal faulting earthquakes will probably occur on the Tibetan Plateau in the future to account for the continuing east-west extension.

\section{Conclusions}

The 2003-2004 Bange earthquake sequence involves a series of normal faulting events with magnitudes larger than 5.0, which occurred on previously unknown faults. InSAR observations provide important constraints on the source parameters and slip distributions. The results indicate that the 2003 earthquake was a normal-faulting event with a right-lateral slip component. The 27 March 2004 Ms 6.2 earthquake was associated with a normal fault striking southwest-northeast and dipping southeast with a moderately oblique right-lateral slip. The 3 July Ms 5.1 event was caused by a normal fault with a slight normal slip component. A calculation of the static stress changes on the fault planes demonstrates that the third earthquake may have been triggered by the previous ones. 
This study indicates that InSAR can provide reliable source parameters of shallow, moderate-sized earthquakes in areas that lack dense seismic networks. Earthquakes with $M \geqslant 5.0$ are common on the Tibetan Plateau. However, because of the sparse seismic station distribution, most of the focal mechanisms that are important for understanding local tectonic activity are unknown. Nevertheless, it is possible to learn more about moderate-sized earthquakes using InSAR, as more SAR data are available from new satellite missions (e.g., Sentinel-1A and Advanced Land Observing Satellite-2).

Acknowledgments: This study was supported by the Spark Programs of Earthquake Sciences granted by the China Earthquake Administration (XH14069Y) and the Special Earthquake Research Project granted by the China Earthquake Administration (201508009). Envisat SAR data are copyrighted by ESA and were provided by ESA under the 'Group on Earth Observations (GEO) Geohazard Supersite initiative' (http://www.earthobservations.org/gsnl.php) with the Category 1 project (C1F.28413). The author would like to thank the editors and three anonymous reviewers for their very constructive comments and suggestions that greatly improved this paper.

Author Contributions: All of the authors participated in editing and reviewing the manuscript. Lingyun Ji led the research and processed the InSAR data. Jing Xu calculated the Coulomb stress change. Lingyun Ji and Chengsheng Yang inverted the coseismic slip distribution. Lingyun Ji and Qiang Zhao analyzed and interpreted the results. All contributed to the writing of this manuscript.

Conflicts of Interest: The authors declare no conflict of interest.

\section{References}

1. The China Earthquake Networks Center's (CENC) Catalogue. Available online: http://data.earthquake.cn/ datashare/csn_catalog_p001_new.jsp (accessed on 1 March 2016).

2. Taylor, M.; Yin, A.; Ryerson, F.J; Kapp, P.; Ding, L. Conjugate strike-slip faulting along the Bangong-Nujiang suture zone accommodates coeval east-west extension and north-south shortening in the interior of the Tibetan Plateau. Tectonics 2003, 22, 1-18. [CrossRef]

3. Zhang, P.Z.; Deng, Q.D.; Zhang, G.M.; Ma, J.; Gan, W.; Min, W.; Mao, F.; Wang, Q. Active tectonic blocks and strong earthquakes in the continent of China. Sci. China Ser. D Earth Sci. 2003, 46 (Suppl. S2), 13-24. (In Chinese)

4. Tapponnier, P.; Zhiqin, X.; Roger, F.; Meyer, B.; Arnaud, N.; Wittlinger, G.; Jingsui, Y. Oblique stepwise rise and growth of the Tibet Plateau. Science 2001, 294, 1671-1677. [CrossRef] [PubMed]

5. Massonnet, D.; Feigl, K. Radar interferometry and its application to changes in the Earth's surface. Rev. Geophys. 1998, 36, 441-500. [CrossRef]

6. Rosen, P.A.; Hensley, S.; Joughin, I.R.; Li, F.K.; Madsen, S.N.; Rodriguez, E.; Goldstein, R.M. Synthetic aperture radar interferometry. Proc. IEEE 2000, 88, 333-380. [CrossRef]

7. Massonnet, D.; Rossi, M.; Carmona, C.; Adragna, F.; Peltzer, G.; Feigl, K.; Rabaute, T. The displacement field of the Landers earthquake mapped by radar interferometry. Nature 1993, 364, 138-142. [CrossRef]

8. Wright, T.J.; Lu, Z.; Wicks, C. Constraining the slip distribution and fault geometry of the Mw 7.9, 3 November 2002, Denali fault earthquake with interferometric synthetic aperture radar and global positioning system data. Bull. Seismol. Soc. Am. 2004, 94, S175-S189. [CrossRef]

9. Biggs, J.; Nissen, E.; Craig, T.; Jackson, J.; Robinson, D.P. Breaking up the hanging wall of a rift-border fault: The 2009 Karonga earthquakes, Malawi. Geophys. Res. Lett. 2010, 37. [CrossRef]

10. Li, Z.; Elliott, J.; Feng, W.; Jackson, J.; Parsons, B.; Walters, R. The 2010 MW 6.8 Yushu (Qinghai, China) earthquake: Constraints provided by InSAR and body wave seismology. J. Geophys. Res. 2011, 116. [CrossRef]

11. Elliott, J.; Nissen, E.; England, P.; Jackson, J.; Lamb, S.; Li, Z.; Oehlers, M.; Parsons, B. Slip in the 2010-2011 Canterbury earthquakes, New Zealand. J. Geophys. Res. 2012, 117. [CrossRef]

12. Wen, Y.; Xu, C.; Liu, Y.; Jiang, G. Deformation and source parameters of the $2015 \mathrm{Mw} 6.5$ earthquake in Pishan, western China, from Sentinel-1A and ALOS-2 Data. Remote Sens. 2016, 8, 1-14. [CrossRef]

13. Werner, C.; Wegmüller, U.; Strozzi, T.; Wiesmann, A. GAMMA SAR and interferometric processing software. In Proceedings of the ERS-Envisat Symposium, Gothenburg, Sweden, 16-20 October 2000.

14. Farr, T.G.; Rosen, P.A.; Caro, E.; Crippen, R.; Duren, R.; Hensley, S.; Kobrick, M.; Paller, M.; Rodriguez, E.; Roth, L.; et al. Shuttle radar topography mission. Rev. Geophys. 2007, 45. [CrossRef]

15. The Consultative Group on International Agricultural Research's Consortium for Spatial Information. Available online: http://srtm.csi.cgiar.org (accessed on 1 March 2016). 
16. Goldstein, R.M.; Werner, C.L. Radar interferogram filtering for geophysical applications. Geophys. Res. Lett. 1998, 25, 4035-4038. [CrossRef]

17. Nof, R.N.; Ziv, A.; Doin, M.P.; Baer, G.; Fialko, Y.; Wdowinski, S.; Eyal, Y.; Bock, Y. Rising of the lowest place on Earth due to Dead Sea water-level drop: Evidence from SAR interferometry and GPS. J. Geophys. Res. 2012, 117. [CrossRef]

18. Rosen, P.A.; Hensley, S.; Zebker, H.; Webb, F.H.; Fielding, E.J. Surface deformation and coherence measurements of Kilauea Volcano, Hawaii, from SIR-C radar interferometry. J. Geophys. Res. 1996, 101, 23109-23125. [CrossRef]

19. Lu, Z.; Dzurisin, D. InSAR Imaging of Aleutian Volcanoes: Monitoring a Volcanic Arc from Space; Springer: Chichester, UK, 2014; p. 390.

20. Jonsson, S.; Zebker, H.; Segall, P.; Amelung, F. Fault slip distribution of the Mw 7.2 Hector Mine earthquake estimated from satellite radar and GPS measurements. Bull. Seismol. Soc. Am. 2002, 92, 1377-1389. [CrossRef]

21. Okada, Y. Surface deformation due to shear and tensile faults in a half-space. Bull. Seismol. Soc. Am. 1985, 75, 1135-1154.

22. Press, W.; Teukolsky, S.; Vetterling, W.; Flannery, B. Numerical Recipes in C, the Art of Scientific Computing; Cambridge University Press: New York, NY, USA, 1992; p. 994.

23. Funning, G.; Parsons, B.; Wright, T.J. The 1997 Manyi (Tibet) earthquake: Linear elastic modelling of coseismic displacements. Geophys. J. Int. 2007, 169, 988-1008. [CrossRef]

24. Lohman, R.B.; Simons, M. Some thoughts on the use of InSAR data to constrain models of surface deformation: Noise structure and data downsampling. Geochem. Geophys. Geosyst. 2005, 6. [CrossRef]

25. Wang, R.; Diao, F.; Hoechner, A. SDM-A geodetic inversion code incorporating with layered crust structure and curved fault geometry. In Proceedings of the EGU General Assembly 2013, Vienna, Austria, 7-12 April 2013.

26. Wang, L.; Wang, R.; Roth, F.; Enescu, B.; Hainzl, S.; Ergintav, S. Afterslip and viscoelastic relaxation following the 1999 M7.4 Izmit earthquake from GPS measurement. Geophys. J. Int. 2009, 178, 1220-1237. [CrossRef]

27. Xu, C.; Liu, Y.; Wen, Y.; Wang, R. Coseismic slip distribution of the $2008 \mathrm{Mw} 7.9$ Wenchuan earthquake from joint inversion of GPS and InSAR data. Bull. Seismol. Soc. Am. 2010, 100, 2736-2749. [CrossRef]

28. Wen, Y.; Xu, C.; Liu, Y.; Jiang, G.; He, P. Coseismic slip in the 2010 Yushu earthquake (China), constrained by wide-swath and strip-map InSAR. Nat. Hazards Earth Syst. Sci. 2013, 13, 35-44. [CrossRef]

29. Motagh, M.; Bahroudi, A.; Haghighi, M.H.; Samsonov, S.; Fielding, E.; Wetzel, H.U. The 18 August 2014 Mw 6.2 Mormori, Iran, Earthquake: A thin-skinned faulting in the Zagros Mountain inferred from InSAR measurements. Seismol. Res. Lett. 2015, 86, 775-782. [CrossRef]

30. Cotton, F.; Archuleta, R.; Causse, M. What is sigma of the stress drop? Seismol. Res. Lett. 2013, 84, 42-48. [CrossRef]

31. Brune, J.N. Tectonic stress and the spectra of seismic shear waves from earthquakes. J. Geophys. Res. 1970, 75, 4997-5009. [CrossRef]

32. Scholz, C.H. The mechanics of Earthquakes and Faulting; Cambridge University Press: New York, NY, USA, 2002.

33. Allmann, B.P.; Shearer, P.M. Global variations of stress drop for moderate to large earthquakes. J. Geophys. Res. 2009, 114. [CrossRef]

34. Ryder, I.; Burgmann, R.; Fielding, E. Static stress interactions in extensional earthquake sequences: An example from the South Lunggar Rift, Tibet. J. Geophys. Res. 2012, 117. [CrossRef]

35. Wang, R.; Lorenzo-Martín, F.; Roth, F. PSGRN/PSCMP-A new code for calculating co-and post-seismic deformation, geoid and gravity changes based on the viscoelastic-gravitational dislocation theory. Comput. Geosci. 2006, 32, 527-541. [CrossRef]

36. Nissen, E.; Elliott, J.R.; Sloan, R.A.; Craig, T.J.; Funning, G.J.; Hutko, A.; Parsons, B.E.; Wright, T.J. Limitations of rupture forecasting exposed by instantaneously triggered earthquake doublet. Nat. Geosci. 2016, 9, 330-336. [CrossRef]

37. Harris, R. Introduction to special section: Stress triggers, stress shadows, and implications for seismic hazard. J. Geophys. Res. 1998, 103, 24347-24358. [CrossRef]

38. Freed, A.M. Earthquake triggering by static, dynamic, and postseismic stress transfer. Annu. Rev. Earth Planet. Sci. 2005, 33, 335-367. [CrossRef] 
39. King, G.C.P.; Stein, R.S.; Lin, J. Static stress changes and the triggering of earthquakes. Bull. Seismol. Soc. Am. 1994, 84, 935-953.

40. Lin, J.; Stein, R.S. Stress triggering in thrust and subduction earthquakes and stress interaction between the southern San Andreas and nearby thrust and strike-slip faults. J. Geophys. Res. 2004, 109. [CrossRef]

41. Elliott, J.R.; Walters, R.J.; England, P.C.; Jackson, J.A.; Li, Z.; Parsons, B. Extension on the Tibetan plateau: Recent normal faulting measured by InSAR and body wave seismology. Geophys. J. Int. 2010, 183, 503-535. [CrossRef]

42. Furuya, M.; Yasuda, T. The 2008 Yutian normal faulting earthquake (Mw 7.1), NW Tibet: Non-planar fault modeling and implications for the Karakax Fault. Tectonophysics 2011, 511, 125-133. [CrossRef]

43. Taylor, M.; Yin, A. Active structures of the Himalayan-Tibetan orogen and their relationships to earthquake distribution, contemporary strain field, and Cenozoic volcanism. Geosphere 2009, 5, 199-214. [CrossRef]

(C) 2016 by the authors; licensee MDPI, Basel, Switzerland. This article is an open access article distributed under the terms and conditions of the Creative Commons Attribution (CC-BY) license (http://creativecommons.org/licenses/by/4.0/). 